\title{
Indoor and Outdoor Concentrations of Bioaerosols and Meteorological Conditions of Selected Salons in Four Areas of Ibadan North Local Government Area
}

\author{
Alli Abosede Sarah, Ana Godson Rowland E. E. \\ Department of Environmental Health Sciences, Faculty of Public Health, University of Ibadan, Ibadan, Nigeria \\ Email address: \\ alliabosede@gmail.com (Alli A. S.), alliabosede@gmail.com (Ana G. R. E. E.)

\section{To cite this article:} \\ Alli Abosede Sarah, Ana Godson Rowland E. E. Indoor and Outdoor Concentrations of Bioaerosols and Meteorological Conditions of \\ Selected Salons in Four Areas of Ibadan North Local Government Area. International Journal of Environmental Monitoring and Analysis. \\ Vol. 5, No. 3, 2017, pp. 83-90. doi: 10.11648/j.ijema.20170503.13
}

Received: April 3, 2017; Accepted: April 18, 2017; Published: June 7, 2017

\begin{abstract}
Microorganisms are ubiquitous in the atmosphere but their concentrations are significantly affected by specific environmental factors. Thus, the characterization of bioaerosol levels in both the indoor and outdoor environment have become an important issue due to their adverse health effects. Therefore this study assessed the indoor and outdoor concentrations of bioaerosols and the meteorological conditions in selected salons in four areas of Ibadan North Local Government Area, Oyo State, Nigeria. This comparative cross-sectional study comprised of onsite observations, meteorological measurements viz: temperature and relative humidity (RH) and microbiological assessment (fungi and bacteria load). Building characteristics and sanitary conditions of salons were assessed using a walk-through observational checklist. A TE-10-890 single stage sampler was used for viable bioaerosol sampling and isolates were identified according to standard methods. Data obtained were analysed using descriptive and inferential statistics with SPSS (version 20). Mold growth and damp roof were observed in less than $20 \%$ and $40 \%$ of salons at the study locations respectively. Mean indoor and outdoor temperature and RH across Agbowo, Mokola, Yemetu and Bashorun were significantly higher than ASHRAE guideline limits. The mean concentrations of bacteria and fungi aerosols were significantly higher indoor than outdoor $(\mathrm{p}<0.05)$. Staphylococcus $\mathrm{spp}$, Bacillus spp, Enterobacteria spp and Flavobacterium spp. were the predominant bacteria species isolated while Aspergillus spp, Penicillium spp, Fusarium spp, and Mucor spp. were the most common fungi species detected in the samples. The study showed that both the indoor and outdoor air were contaminated with bacteria and fungi, therefore it is important to control the environmental factors that support microbial growth in order to curtail occurrence of possible adverse effects they may have on health.
\end{abstract}

Keywords: Bacteria, Fungi, Bioaerosol, Salons, Indoor, Outdoor

\section{Introduction}

Most people spend approximately $90 \%$ of their time indoors whether at home, work or schools where they are continuously exposed to the microbial content of this environments [1]. Previous research has indicated that human occupancy increases the airborne bacterial load and leaves a distinctly human microbial signal inside buildings $(2,3)$. Specific activities like talking, sneezing, coughing, walking, washing and toilet flushing can generate airborne biological particulate matter [4]. Many genera are also emitted by indoor sources like animals, flowerpots, wastebaskets and indirectly from dust perturbations [5]. Airborne microbes attach to dust particles, condense and enter human body directly via inhalation or indirectly via ingestion of contaminated foods and water resulting in the development of diseases and toxic reactions [6].

Microorganisms are ubiquitous in the built environment; covering virtually all surfaces and are abundant in air, thereby entering indoor areas by passive ventilation or by ventilation systems [5]. Generally, microbes enter into the atmosphere from natural and anthropogenic sources, but their survival and distribution depend on their cell structure and meteorological conditions $[7,8]$. The contribution of outdoor air to indoor air pollution depends on the concentration and composition of bioaerosols present in the outdoor air. 
However, previous researches showed that even if the outdoor concentrations affect the indoor air; the indoor-tooutdoor $(\mathrm{I} / \mathrm{O})$ ratio will mostly be greater than one. This is because several sources of indoor bioaerosols contribute to the increase in the levels of indoor bioaerosol [3, 9].

Bioaerosols are particles of biological origin suspended in air. The most studied bioaerosols are the airborne bacteria and fungi which are responsible for the biological contamination of indoor environments [10]. They are either dangerous as pathogenic living cells or cause sensitivities as a result of prolonged exposure [11]. Therefore, the characterization of bioaerosol levels in both indoor and outdoor environments have become an important issue due to their adverse health effects [2]. High concentrations of microorganisms in the air can be toxic; however, some microorganisms can cause serious diseases even at low concentrations $[10,12]$. Bioaerosols have been shown to cause about $30 \%$ of health problems related to indoor air quality, and can breed allergies, SBS symptoms ("sick building syndrome"); dermatosis and respiratory diseases $[13,14]$.

Air sampling of microorganisms is a popular method of conducting microbial examinations, as it allows a direct toxicological evaluation with results that can be related to a concentration expressed in colony forming units per cubic meter. Furthermore, monitoring of environmental factors such as temperature and relative humidity can be a useful tool to explain possible bioaerosol sources [2]. Since bacteria and fungi require specific environmental conditions to grow and propagate, their concentrations are significantly affected by these factors $[8,15]$.

Therefore this study observed the indoor and outdoor concentration of bioaerosols and meteorological conditions of selected salons in four areas of Ibadan North Local Government Area, where hairdressers spend several hours working in enclosed spaces every day and where microbiological quality of indoor air can influence their health and physical condition.

\section{Material and Methods}

\subsection{Study Area}

Ibadan North Local Government Area (IBNLG) is located in Ibadan, the capital of Oyo State, Nigeria. It covers a large expanse of land with an area of about 420sqkilometers is heavily populated with an estimated population of 316,612 people, most of which are from the Yoruba ethnic group; other ethnic groups constitute smaller proportions of this urban population [16]. IBNLGA is the commercial centre of the state with a fluctuating traffic flow that peaks at two periods of the day. Traffic consisted primarily of trucks, cars, two wheelers (motorbikes) and pedestrian traffic. The major occupations of residents in the area are trading and artisan work in small scale trades. The study population included hairdressers above 18 years of age in IBNLGA who had given informed consent to participate in the study.

\subsection{Study Design}

A cross-sectional study design was adopted in this study. Four areas in Ibadan North Local Government (IBNLG) were selected using multi-stage method. A preliminary survey was carried out to obtain information on the total number of salons in the selected areas and salons were selected using the proportionate sampling technique. The study comprised of onsite observations, meteorological measurements viz: temperature and relative humidity, microbiological assessment (fungi and bacteria load).

\subsection{Salon Selection}

There are a total number of 257 salons in the four selected areas of IBNLG. Microbiological air monitoring was carried out in $25 \%$ of the salons in each of the areas.

\subsection{On-site Observations}

An observational checklist was used to capture some environmental health indicators focusing on the building characteristics and sanitary conditions of the salons.

\subsection{Meteorological Parameters}

Room Temperature (RT) and Relative Humidity (RH) were taken using a Thermo-Scientific pDR-1500 particulate monitor; a multi-function device designed to combine the functions of PM, temperature and humidity meters. RT was measured in degrees Celsius $\left({ }^{\circ} \mathrm{C}\right)$ while $\mathrm{RH}$ was measured in percentage $(\%)$. The measurements were taken in the morning (9-11am) and in the afternoon (12-2pm) for a period of two months.

\subsection{The Microbial Air Sampling}

A TE-10-890 Single stage microbial air sampler was used to collect samples for microbial analysis from a height of $1.5 \mathrm{~m}$ from the surface to simulate human breathing zone. Samples were collected twice a day (9-11am and 12-2pm) in duplicate for bacteria as well as fungi for 8 weeks. Measurements were obtained at the centre of the shop (indoor) and at the entrance (outdoor) between August and October 2015.

\subsubsection{Description of Operation}

Collection plates were prepared aseptically by pipetting 27 $\mathrm{mL}$ of sterile agar (nutrient agar for bacteriological analysis and potato dextrose agar for fungi analysis). A collection plate was inserted on the stage of the sampling instrument and the air to be sampled was sucked into the inlet cone and flows through the orifices stage into the media. Thus, viable particles were retained on the agar plates. All agar plates were then placed in an inverted position to prevent condensation drip. The edges of the plates were sealed with paper tape wrapped in foil paper in an air tight box and transported to the laboratory.

The plates were incubated at $35^{\circ} \mathrm{C}$ for 2 days for bacteria and 5 days for fungi. The total plate counts were taken after 
incubation. Sampling was carried out at a flow rate of 2 for 30 minutes; this was used to estimate the mean number of viable particles (aerobic bacteria and/or fungi) per unit volume of air. The airborne bacterial and fungal concentrations were calculated and expressed as colony forming units per cubic meter of air $\left(\mathrm{cfu} / \mathrm{m}^{3}\right)$.

\subsubsection{Microbial Identification}

Bacterial identification was based primarily on morphology, gram staining, biochemical tests, growth characteristic and culture characteristics. General detection and enumeration media were used in the collection of bacteria. Plates were replicated on differential or selective media for identification after the organisms have been collected. In addition, other media for the detection and enumeration of bacteria were used to discriminate for a general class of microorganisms by inhibiting or eliminating other microorganisms, selective media containing an antibiotic or other growth restricting chemical were used to distinguish among species. Differential media were also used; they contain indicators that permit the recognition of microorganisms with particular metabolic activities.

Light microscope was used to determine the colonial features and the morphological structures of the fungi. The determination of the morphological structures of fungi was carried out on material mounted in lactophenol based on micromorphology and using the books by $[17,18]$.

\section{Results}

\subsection{Building Characteristics and Sanitary Conditions of Salons}

Table 1 shows the building characteristics of salons in the study locations. It was observed that mold growth was present in less than $20 \%$ of the salons visited. Damp roof was observed in less than $40 \%$ of salons in Agbowo, Mokola and Yemetu, while damp roof was absent in salons at Bashorun.

The sanitary conditions of salons in the study areas is depicted in Table 2. Salons in Agbowo had the highest proportion $(29 \%)$ of waste bin, followed by Mokola
(23\%), Bashorun (17\%) and Yemetu (16\%). Across the study locations, majority (94\%) of the salons lacked pipe water system, consequently, water closet was observed in only $36 \%$ of the salons.

Table 1. Building characteristics of salons in study locations.

\begin{tabular}{lllll}
\hline Building characteristics & Agbowo & Mokola & Yemetu & Bashorun \\
\hline Dust on furnishing & +++ & +++ & ++ & ++ \\
Damp roof & ++ & ++ & ++ & - \\
Presence of mold growth & + & + & + & + \\
\hline
\end{tabular}

-: Absent in salons; +: Present in less than $20 \%$ of salons; ++ : Present in less than $40 \%$ of salons; +++ : Present in less than $60 \%$ of salons

Table 2. Sanitary conditions at the salons.

\begin{tabular}{|c|c|c|c|c|c|}
\hline \multicolumn{2}{|c|}{ Sanitary conditions } & \multicolumn{4}{|c|}{ Proportion of salons (\%) } \\
\hline & Options & Agbowo & Mokola & Yemetu & Bashorun \\
\hline \multirow{3}{*}{$\begin{array}{l}\text { Liquid } \\
\text { waste } \\
\text { disposal }\end{array}$} & In drainage & 54 & 54 & 40 & 63 \\
\hline & On the ground & 35 & 43 & 56 & 37 \\
\hline & $\begin{array}{l}\text { Refuse dump/ } \\
\text { bush }\end{array}$ & 11 & 3 & 4 & 0 \\
\hline \multirow{4}{*}{$\begin{array}{l}\text { Solid waste } \\
\text { disposal } \\
\text { Water } \\
\text { supply }\end{array}$} & Waste bin & 29 & 16 & 23 & 17 \\
\hline & Carton/ Nylon & 71 & 84 & 77 & 83 \\
\hline & Pipe & 12 & 2 & 0 & 8 \\
\hline & Manual & 88 & 98 & 100 & 92 \\
\hline \multirow{3}{*}{$\begin{array}{l}\text { Sanitary } \\
\text { facilities }\end{array}$} & Water closet & 35 & 33 & 29 & 48 \\
\hline & Latrine & 35 & 27 & 29 & 25 \\
\hline & $\begin{array}{l}\text { Open } \\
\text { defaecation }\end{array}$ & 30 & 40 & 42 & 27 \\
\hline
\end{tabular}

\subsection{Meteorological Conditions (Temperature and Relative Humidity)}

Table 3 shows the mean temperature and relative humidity (RH) measurements for the indoor and outdoor environments at the selected salons. Relative humidity was observed to be higher indoors than outdoors. The daily mean values for indoor RH were between $67.2 \%$ and $75.3 \%$ as compared to between $66 \%$ and $73.1 \%$ for outdoor RH. The mean indoor and outdoor temperature and $\mathrm{RH}$ (Table 3) were above ASHRAE guideline limits of $26^{\circ} \mathrm{C}$ and $65 \%$ respectively. The morning RH levels significantly exceeded the afternoon levels for both indoor and outdoor salon environments $(\mathrm{p}<$ $0.05)$.

Table 3. Mean ( $\pm S D)$ indoor and outdoor relative humidity $(\%)$ and temperature $\left({ }^{\circ} \mathrm{C}\right)$ of selected salons.

\begin{tabular}{|c|c|c|c|c|c|c|c|c|}
\hline \multirow[t]{2}{*}{ Area } & \multicolumn{2}{|l|}{ Indoor (\%) } & \multicolumn{2}{|c|}{ Outdoor (\%) } & \multicolumn{2}{|l|}{ Indoor $\left({ }^{\circ} \mathrm{C}\right)$} & \multicolumn{2}{|c|}{ Outdoor $\left({ }^{\circ} \mathrm{C}\right)$} \\
\hline & Morning & Afternoon & Morning & Afternoon & Morning & Afternoon & Morning & Afternoon \\
\hline Agbowo & $74.3 \pm 6.4$ & $67.3 \pm 5.7$ & $72.6 \pm 6.4$ & $66.1 \pm 5.3$ & $27.2 \pm 1.9$ & $29.9 \pm 1.5$ & $27.7 \pm 2.1$ & $30.1 \pm 1.6$ \\
\hline Mokola & $74.6 \pm 6.2$ & $69.1 \pm 3.7$ & $73.1 \pm 5.7$ & $67.5 \pm 2.8$ & $27.3 \pm 1.4$ & $29.0 \pm 1.2$ & $27.6 \pm 1.3$ & $29.2 \pm 1.3$ \\
\hline Yemetu & $75.3 \pm 7.9$ & $67.8 \pm 6.5$ & $74.2 \pm 7.2$ & $66.6 \pm 6.5$ & $27.1 \pm 2.2$ & $29.6 \pm 1.6$ & $27.5 \pm 2.1$ & $29.9 \pm 1.9$ \\
\hline Bashorun & $71.8 \pm 3.4$ & $67.2 \pm 1.6$ & $70.1 \pm 3$ & $66.0 \pm 1.7$ & $27.8 \pm 1.1$ & $29.5 \pm 0.5$ & $28.2 \pm 0.9$ & $29.7 \pm 0.7$ \\
\hline
\end{tabular}

\subsection{Indoor and Outdoor Airborne Bacterial Burden Among Selected Salons}

Figure 1-4 shows the variation in mean indoor and outdoor total bacteria and fungi counts among salons monitored as compared to the American Industrial Hygiene Association (AIHA) guideline. A positive correlation between indoor total bacteria counts $(\mathrm{TBC})$ and indoor relative humidity was observed $\quad(r=0.375, \quad p<0.01)$, with coefficient of determination $r^{2}$ of 0.140 indicating that relative humidity was responsible for $14 \%$ of the increase in TBC. The scatter plot diagram illustrating this result is shown in Figure 5. Indoor and outdoor TBC throughout the period of monitoring were significantly higher than the guideline limits (figure 12). Also, TBC and TFC were significantly higher indoor than 
outdoor $(\mathrm{p}<0.01)$.

TFC variation observed across the study period were within the guideline limit (Figure 3-4). There was a moderate positive correlation between indoor TFC and indoor Relative humidity $(\mathrm{r}=0.261, \mathrm{p}<0.05)$, with coefficient of

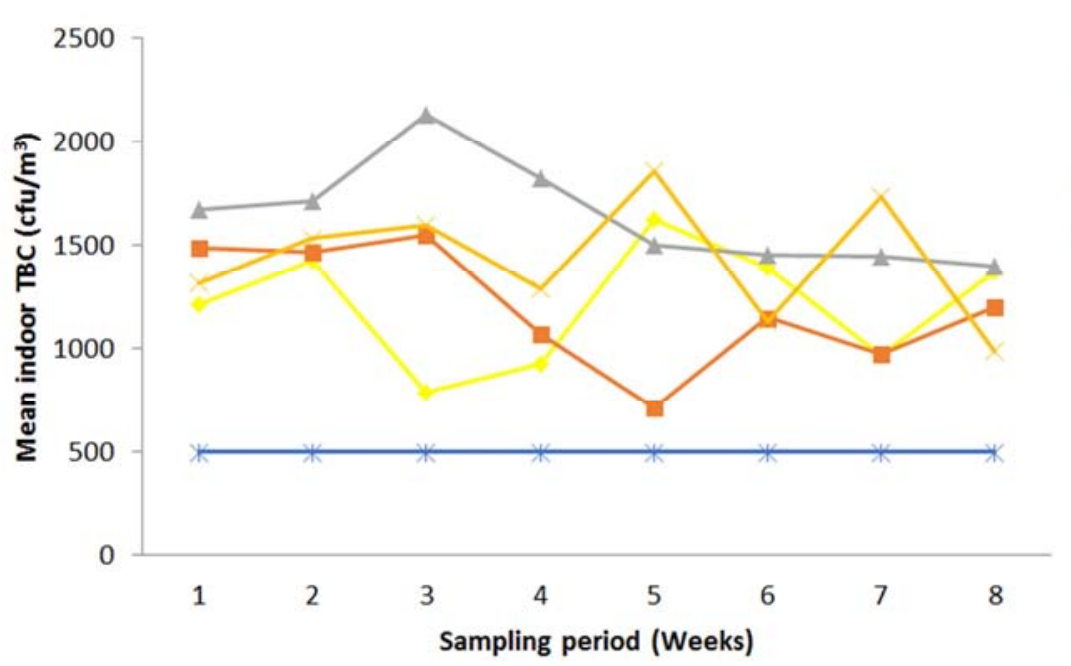

Figure 1. Weekly indoor trends of Total Bacteria Counts (TBC) across sampling locations compared with AIHA guideline limits.

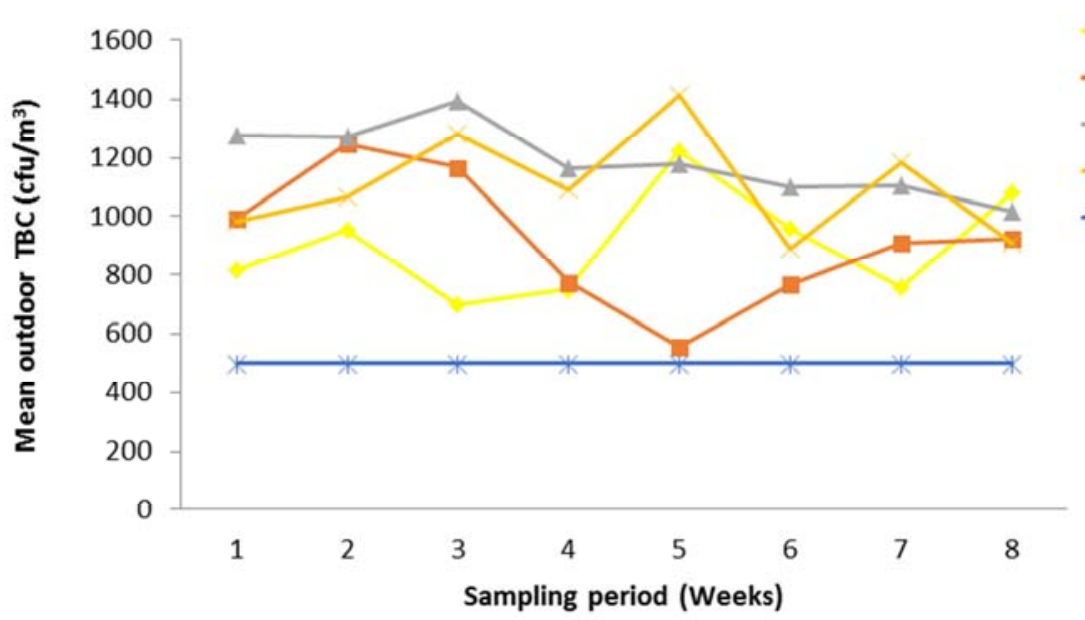

Figure 2. Weekly outdoor trends of Total Bacteria Counts (TBC) across sampling locations compared with AIHA guideline limits.

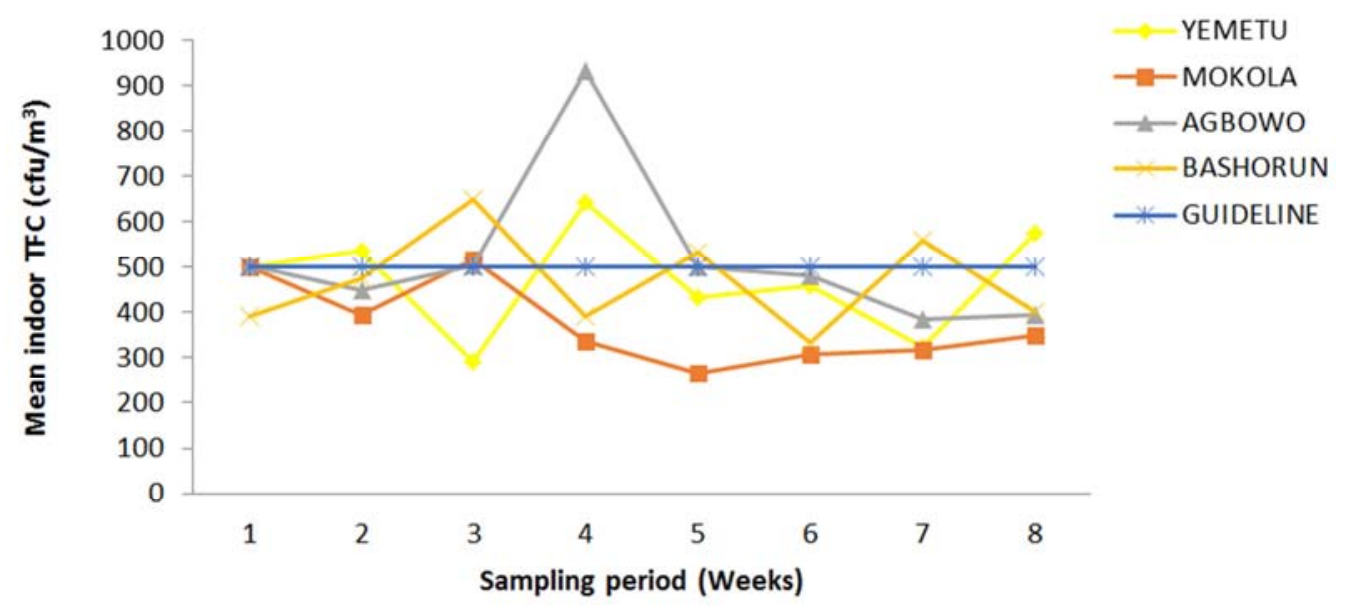

Figure 3. Weekly trends in indoor Total Fungi Counts (TFC) across sampling locations compared with AIHA guideline limits. 


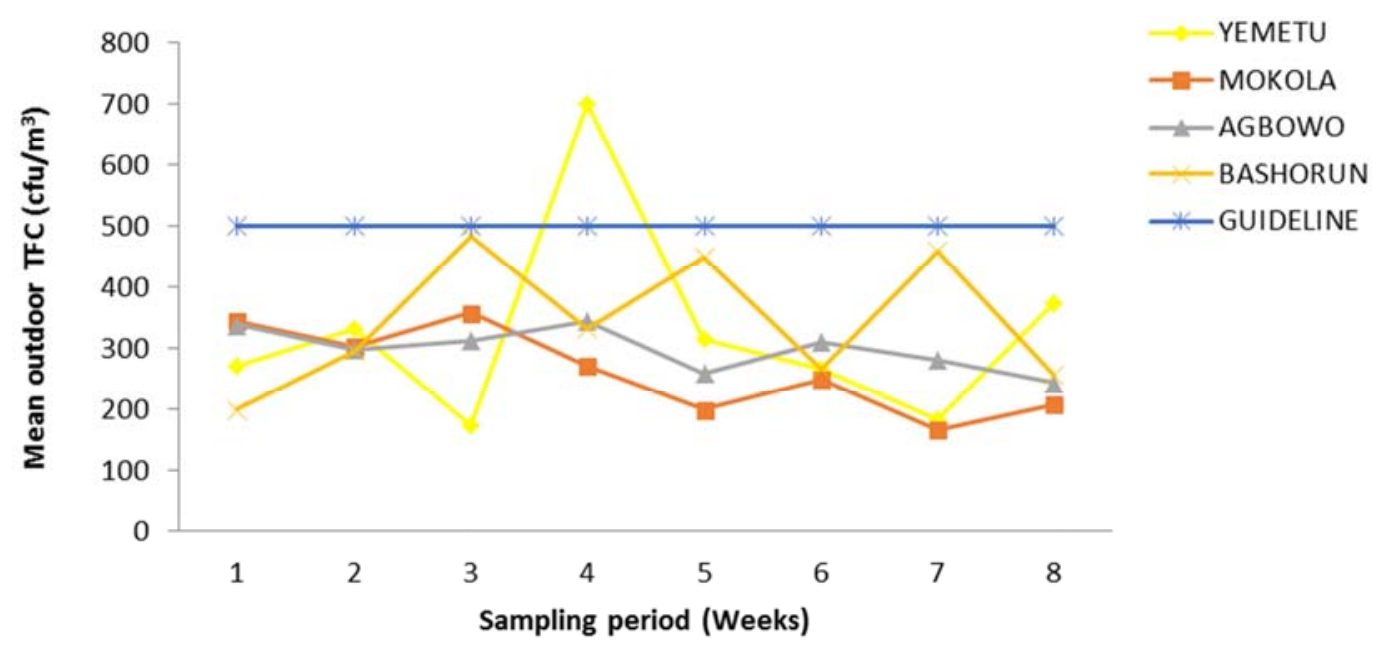

Figure 4. Weekly trends in outdoor Total Fungi Counts (TFC) across sampling locations compared with AIHA guideline limits.

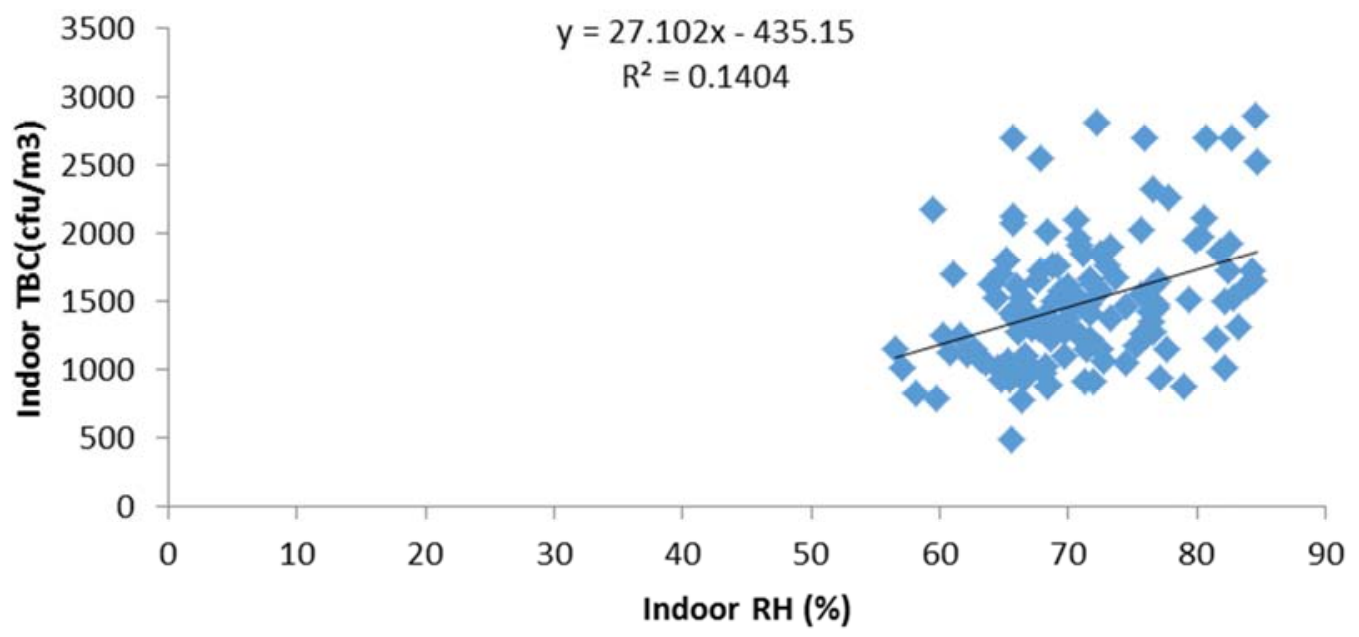

Figure 5. Relationship between Indoor TBC and Indoor relative humidity.

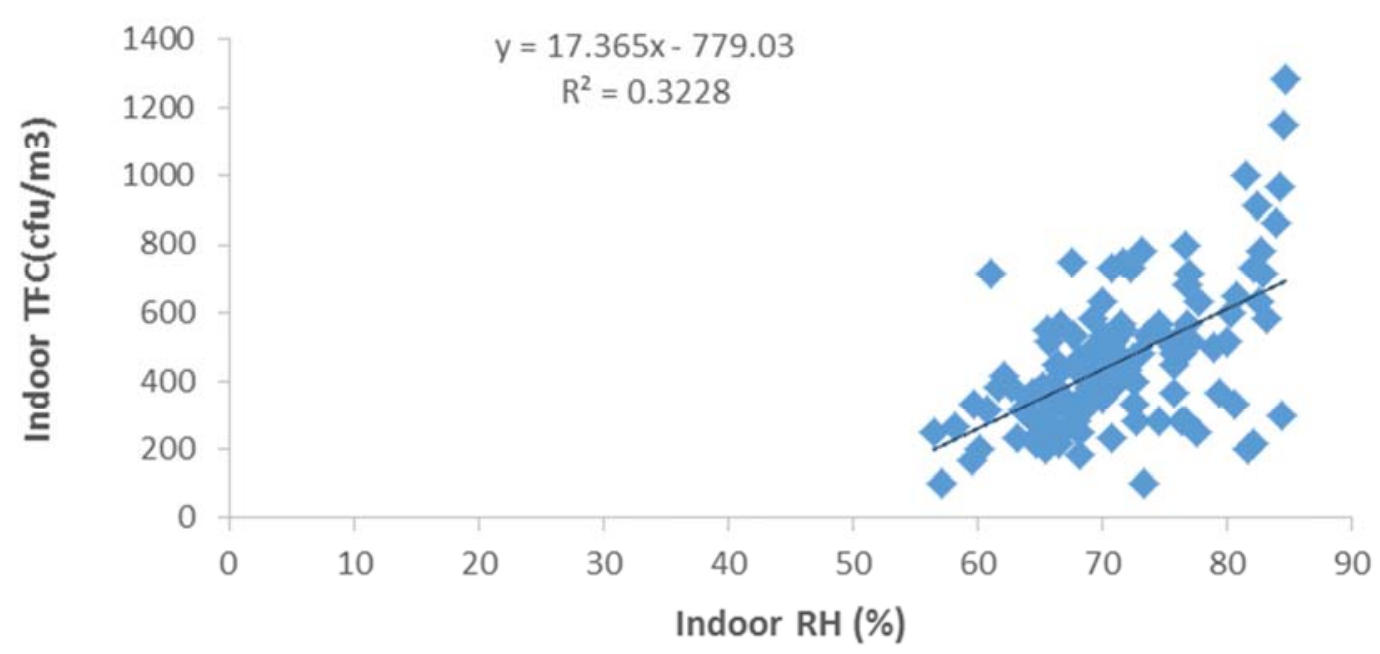

Figure 6. Relationship between Indoor TFC and Indoor relative humidity.

\subsection{Predominant Bacteria and Fungi}

As shown in Figure 7, the predominant bacteria were, Staphylococcus spp, Bacillus spp, Enterobacteria spp and Flavobacterium spp. In the morning, Staphylococcus spp and
Flavobacterium spp were respectively present in $85 \%$ and $65 \%$ of the salons sampled as compared to Bacillus spp $(60 \%)$ and Enterobacteria spp (30\%). While in the afternoon, Staphylococcus spp. was present in $60 \%$ of the salons 
sampled as compared to Bacillus spp. (40\%), Flavobacterium $\quad$ spp (30\%) and Enterobacteria spp (25\%).

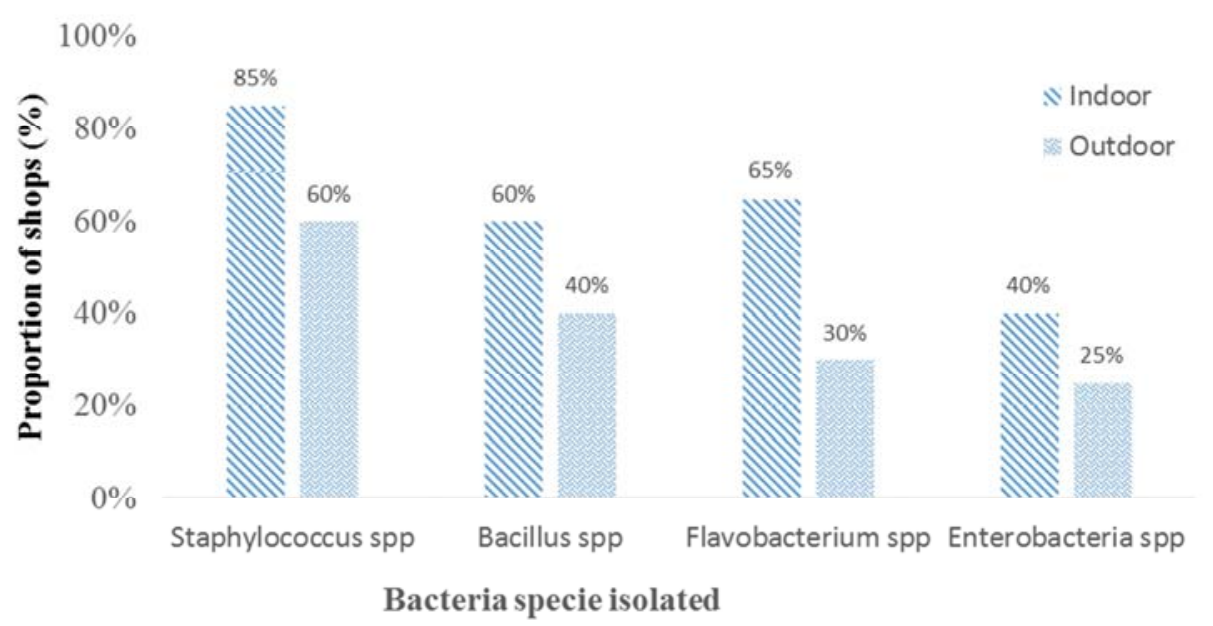

Figure 7. Predominant bacteria species observed during the sampling periods.

The predominant fungi species isolated at the salons is illustrated in Figure 8. In the morning, Aspergillus spp, Fusarium spp and Penicillium spp were observed in $60 \%, 45 \%$ and $60 \%$ of the salons respectively as compared to Myrothecium (20\%) and Mucor (30\%). In the afternoon, Penicillium spp, Aspergillus spp and Fusarium spp were observed in 40\% and 35\% of the salons respectively, as compared to the other fungi species.

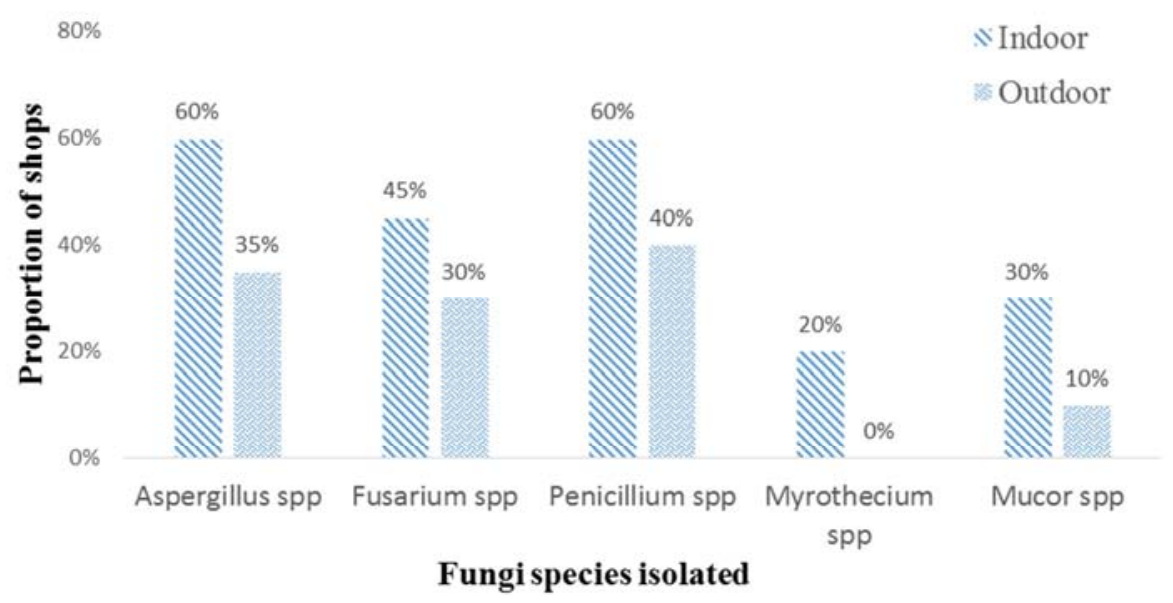

Figure 8. Predominant fungi species observed during the sampling periods.

\section{Discussion}

\subsection{Building Characteristics and Sanitary Conditions in Salons}

The presence of dampness and moldy patches have been established to be associated with indoor fungal growth [3, 12]. The on-site observations showed that mold growth and damp roof were present in less than $20 \%$ and $40 \%$ of the salons respectively. The presence of mold growth and damp roof significantly correlated with the fungi count recorded in the salons. This was corroborated by [14].

Poor sanitary conditions in salons can increase risk of exposure to hazards and may lead to environmental pollution [19]. This is supported in the present study where a high proportion $(76 \%)$ of the salons were observed not to have appropriate waste bins. The hair wastes were stored in paper cartons or polythene bags and disposed or burnt whenever the cartons were filled up. The general opinion of hairdressers to this method of waste collection was that it was easy and cost effective to simply throw the nylon/carton on any available dump site. This agrees with the findings of [20] on assessment of hair barbing waste management practices in Bama, Borno state, Nigeria. The inadequate water supply observed among the salons might be due to the lack of generalized pipe water system and other possible water sources in the study areas. This was observed to negatively affect the sanitation practices in the salons. Similar findings were reported by [21].

\subsection{Microbial Burden in Salons}

Microorganisms being ubiquitous are continually introduced into the environment and could be easily spread between hairdressers and their clients through contact with 
unwashed hands, soiled equipment or contact with blood and other body substances [22, 23]. Exposure to bio-aerosols can result in respiratory disorders and other adverse health effects such as hypersensitivity pneumonitis and toxic reactions, making efficient monitoring crucial $[12,24]$.

The indoor and outdoor TBC in this study (Figure 1-2) were above the guideline stipulated by American Industrial Hygiene Association (AIHA). This is in line with the findings of $[9,11]$. The bacteria and fungi counts were significantly higher in the morning than afternoon and this might be as a result of higher humidity levels in the morning which favoured their growth. As indicated in other studies, environmental factors, especially dampness enhance microbial growth and multiplication [4, 13]. The present study also showed that the bacterial concentration was significantly $(\mathrm{p}<0.05)$ higher indoor than outdoor as was the case in similar studies $[6,25]$. This could be attributed to the fact that hairdressers spent most of their time indoor engaged in different types of activities and the numerical influx of customers visiting the salon on daily basis. This is in accordance with the findings of [1] who reported that human activities was responsible for high bacteria counts indoors compared to the observed outdoor counts. In accordance with other studies $[9,11]$ the indoor to outdoor ratio for airborne bacteria in this study, was greater than one in all the sampling locations indicating that the high bacterial count can be attributed to various activities carried out within the averagely small salon shops along with the presence of humans, salon tools and equipment.

In all the sampling locations, the total bacteria count were higher than the total fungi count for both the indoor and outdoor environments as corroborated by Yassin and Almouqatea, (2010). The overall mean TFC (457.3 \pm 199.8 $\mathrm{cfu} / \mathrm{m}^{3}$ ) across the four sampling locations was lower than the recommended guideline limit set by AIHA. This is consistent with the findings of [26] on assessment of airborne bacteria and fungi in an indoor and outdoor environment. Similarly, in a study conducted by [27] fungi levels were reported to be lower than the AIHA limit.

Indoor temperature and relative humidity correlated positively with airborne fungi while indoor temperature correlated negatively with bacteria. This is in line with the findings of [6]. The association observed between $\mathrm{RH}$ and TFC $\left(r^{2}=0.323\right)$; RH and TBC $\left(r^{2}=0.134\right)$ explains that $\mathrm{RH}$ was responsible for $32.3 \%$ and $13.4 \%$ increase in TFC and TBC respectively. Similar conclusion was made by $[11,27]$.

\subsection{Airborne Microflora Component of the Studied Salons}

Bioaerosols have potential allergenic or immunotoxic characteristics and are a probable cause of airborne infectious illnesses, especially in people with impaired or susceptible immune systems [10]. Therefore, knowledge about the prevalence of microflora in salons and understanding the types of infections and allergies caused by bioaerosols is of utmost importance. The findings of this study revealed that the predominant bacteria species isolated from indoor and outdoor salon environments across all locations were both Gram positive and Gram negative bacteria belonging to genus Bacillus, Staphylococcus, Flavobacterium and Enterobacteria.. Similar findings were reported in the studies by $[9,22]$. These bacteria isolates have been reported to be abundant on human skin, gastro intestinal tract and sometimes in soil and air further suggesting human sources $[25,26]$.

Staphylococcus sp. isolated from all the salons, is a normal habitat of the skin, although exposure to high density could cause disease in humans. This bacterium has been shown to cause various pus-forming diseases in humans such as boils, carbuncles, foliculities, impetigo contagiosa and scalded-skin syndrome [24].

Predominant fungi species isolated from both indoor and outdoor environments among salons in Agbowo, Mokola, Yemetu and Bashorun were Aspergillus spp, Fusarium spp Penicillium spp, Mucor spp and Myrothecium spp. This is in line with the findings of $[22,27]$. Some of the fungi species like Aspergillus and Penicillium are opportunistic pathogens for humans and are often associated with clinical manifestations such as respiratory allergies, asthma and conjunctivitis [15, 25]. They are also indicators of indoor dampness and are associated with sick building syndrome $[10,13]$. Fusarium spp are soil fungi that require a wet indoor environment to grow, which can cause mycotoxicosis, respiratory allergies and skin infections [7].

\section{Conclusions}

A high proportion (76\%) of salons visited lacked appropriate waste bins reflecting poor waste management system in the salons. From these findings, the hygienic practices in these hairdressing salons were far below expected standards implying that the hairdressers were ignorant or less informed of the risks involved in their work.

The levels of temperature and relative humidity were significantly above the guideline limit. The microbiological air quality in the investigated salons was differentiated and changed significantly during the course of the day. The concentrations of bacteria aerosols in the salons were higher than the slow growing fungi and consequently exceeded AIHA stipulated guideline limit. Also, the concentrations of bacteria and fungi were higher in the morning than afternoon. Both the indoor viable bacteria and fungi concentration were higher than the outdoor concentration. The high levels of relative humidity and bacteria in salons indicated that the indoor environment provided more favourable conditions for the survival of bioaerosols. Staphylococcus spp was the most frequently occurring bacteria followed by Flavobacterium spp; while Aspergillus spp and Penicillium spp were the predominant fungi species in the salons. Fungi isolated were associated with allergies and respiratory tract infections. There is an urgent need for health education by public health agencies through training workshops and seminars for salon workers about possible sources of hazards in order to curtail occurrence of possible adverse health effects. Also, routine indoor air quality monitoring and good sanitary practices in hair salons should be encouraged to checkmate their pollution levels. 


\section{References}

[1] Rintala, H., Pitkaranta, M., Toivola, M., Paulin, L. and Nevalainen, A. 2008. Diversity and seasonal dynamics of bacterial community in indoor environment. BMC Microbiology 56 (8): 1-13.

[2] Stetzenbach, L. D., Buttner, M. P. and Cruz, P. 2004. Detection and enumeration of airborne biocontaminants. Current Opinion in Biotechnology 15: 170-174.

[3] Srikanth, P., Sudharsanam, S. and Steinberg, R. 2008. Bioaerosols in indoor environment: Composition, health effects and analysis. Indian Journal of Medical Microbiology 26 (4): 302-312.

[4] Samuel, F. H. and Abayneh, M. M. 2014. Microbiological Quality of Indoor Air in University Libraries. Asian Pac J Trop Biomed 4 (1): S312-S317.

[5] Bowers, R. M., McLetchie, S., Knight, R. and Fierer, N. 2011. Spatial variability in airborne bacterial communities across land-use types and their relationship to the bacterial communities of potential source environments. ISMEJ 5: 601612 .

[6] Frankel, M., Gabriel, B., Michael, T., Sine, G., Erik, W. H. and Anne, M. M. 2012. Seasonal Variations of Indoor Microbial Exposures and Their Relation to Temperature, Relative Humidity, and Air Exchange Rate. Applied and Environmental Microbiology 78 (23): 8289-8297.

[7] Abdel-Hameed, A. and Khoder, M. 2001. Suspended particulates and bioaerosols emitted from an agricultural nonpoint source. J. Environ. Monit. 3: 206-209.

[8] Mouli, P. C., Mohan, S. V. and Reddy, S. J. Assessment of microbial (bacteria) concentrations of ambient air at semi-arid urban region: influence of meteorological factors. AEER 2005; 3: 139-149.

[9] Mentese, S., Munevver, A., Abbas, Y. R. and Gulen, G. 2009. Bacteria and Fungi levels in various indoor and outdoor environments in Ankara, Turkey. Clean 37 (6): 487-493.

[10] Hoseinzadeh, E., Mohammad, R. S., Sayed, A. G., Mohammad, Y. A. and Ghodratollah, R. 2013. Evaluation of Bioaerosols in Five Educational Hospitals Wards Air in Hamedan, During 2011-2012. Jundishapur Journal of Microbiology 6(6): 1-8.

[11] Katiyar, V. 2013. Assessment of indoor air micro-flora in selected schools. Advances in Environmental Research 2 (1): 61-80.

[12] Gorny, R. L., Reponen, T., Willeke, K., Schmechel, D., Robine, E., Boissier, M. and Sergey, A. G. 2002. Fungal fragments as indoor air biocontaminants. Applied and Environmental Microbiology 68 (7): 3522-3531.

[13] Schwab, C. J. and Straus D. C. 2003. The roles of Penicillium and Aspergillus in Sick building syndrome. Advances in Applied Microbiology 55: 215-238.
[14] Yazicioglu, M., Asan, A., Ones, U., Vatansever, U., Sen, B., Ture, M., Bostancioglu, M., Pala, O. 2004. Indoor air Fungal spores and home characteristics in asthmatic children from Edirne Region of Turkey. Journal of Allergy and Clinical Immunology 32 (4): 197-203.

[15] Chao, H. H. Schwartz, H. A. and Milton, D. K. 2002. Population and determinants of airborne fungi in large office buildings. Environmental Health Perspectives 110: 777-78.

[16] National Population Commission (NPC). 2006. Population distribution by sex, state, LGAs and senatorial district: 2006 census priority tables (Vol 3). Retrieved April 19, 2015 from www.population.gov.ng/index.php/censuses.

[17] Barnett, H. L. 1960. Illustrated genera of imperfect fungi. Burgess Publishing Company, USA.

[18] Ellis, M. B., Ellis P. J. 1985. Microfungi on land plants. Macmillan Publishing Company, USA.

[19] Betson, G. and Stenberg, B. 2012. Self-reported occupational health problems and factors affecting compliance with occupational health and safety requirements among barbers and hairdressers in Ilala Municipality, Dar es Salaam, Tanzania. MSc. Project. Department of public health and clinical medicine. Umea University. xi $+47 \mathrm{pp}$.

[20] Alfred D. M. 2015. Assessment of Hair Barbing Salon Waste Management Practices In Bama Township of Borno State, Nigeria. International Journal for Innovation Education and Research 3 (5): 109-114.

[21] Imoro, M. 2015. Sanitation Management in Salons in the Upper West Region: An Assessment of Disease Prevention Strategies and Safety Promotion Measures. Journal of Biology, Agriculture and Healthcare 5 (19): 47-58.

[22] Oguntibeju, O. O., Enemuor, S. C., Ojih, M. I. and Isah, S. 2013. Evaluation of bacterial and fungal contamination in hairdressing and beauty salons. AJMR 7(14): 1222-1225.

[23] Mbaj, C. S., Obeagu, E. I., Ochei, K. C. and Iheke, S. O. 2014. Evaluation of Microbial Contamination of Tools Used In Hair Dressing Salons in Michael Okpara University of Agriculture, Umudike, Abia State. IOSR Journal of Dental and Medical Sciences (IOSR-JDMS) 13 (7): 22-27.

[24] Ekhaise, F. O and Ogboghodo, B. I. 2011. Microbiological Indoor and Outdoor Air Quality of Two Major Hospitals in Benin City, Nigeria. Sierra Leone Journal of Biomedical Research 3 (3): 169-174.

[25] Soto, T., Rosa, M. G. M., Alejandro, F., Jeronima, V. S., Jose, C. and Gacto, M. 2009. Indoor airborne microbial load in a Spanish university (University of Murcia, Spain). Anales de Biologia 31: 109-115.

[26] Yesufu, L. A., Gideon, A. O. and Umar Z. O. 2013. Indoor air quality and respiratory problems experienced by workers in a typical commercial environment. International Journal of Environmental Monitoring and Analysis 2 (8): 212-222.

[27] Yassin, M. F. and Almouqatea, S. 2010. Assessment of airborne bacteria and fungi in an indoor and outdoor environment. Int. J. Environ. Sci. Technology 7 (5): 535-544. 